\title{
28 Research Square \\ Fruit and Vegetable Intakes and Sleep in Linkage With Cognition Among Older Adults in China
}

\section{Chen Bai}

Renmin University of China

\section{Yuning Xie}

Renmin University of China

Danan Gu ( $\sim$ gudanan@yahoo.com )

United Nations

\section{Research Article}

Keywords: Fruit and vegetable intakes, Sleep quality, Sleep duration, Cognitive impairment, Older adults, CLHLS

Posted Date: November 15th, 2021

DOI: https://doi.org/10.21203/rs.3.rs-1064592/v1

License: @ (i) This work is licensed under a Creative Commons Attribution 4.0 International License. Read Full License 


\section{Abstract}

Background: Identifying factors associated with cognitive impairment among older adults is critical. This study aims to examine associations of fruit and/or vegetable intake ( $\mathrm{FVI})$, sleep quality and duration, and their interactions with cognitive performance among older adults in China.

Methods: We utilize nationwide datasets in 2008 and 2011 in China to examine associations between sleep quality and duration, $\mathrm{FVI}$, and cognitive impairment. Interactions between sleep and FVI on cognitive performance are also examined. All analyses are further stratified by gender, age group, and urban-rural residence.

Results: When all covariates are fully adjusted for in the cross-sectional analyses, frequent FVI is associated with a $29 \%$ lower risk of cognitive impairment compared with less frequent $\mathrm{FVI}$, and daily sleeping durations of $\leq 6 \mathrm{~h}$ and $\geq 10 \mathrm{~h}$ are associated with a $13 \%$ and a $51 \%$ higher risk of cognitive impairment, respectively, as compared with the duration of $8 \mathrm{~h}$. Sleep quality is not significantly associated with cognitive impairment compared with fair/poor sleep quality when all covariates are adjusted, though it is associated with a $31 \%$ lower risk when only demographics are controlled for. Interaction analyses reveal that frequent FVI offsets the higher risk of cognitive impairment for poor sleep quality and excessive sleep durations. Subgroup analyses show a generally similar pattern for both sexes but a more pronounced association for young older adults than for oldest-old adults. The patterns of the interactions of $\mathrm{FVI}$, sleep quality, and sleep duration with cognitive impairment differ by urban-rural residence. However, associations of good sleep quality, adequate sleep duration, and frequent FVI with the incidence of cognitive impairment over a 3-year follow-up period are mostly not significant.

Conclusions: The positive association of good sleep quality, appropriate sleep duration, frequent $\mathrm{FVI}$, with good cognitive is mainly cumulative or long-term. Frequent FVI could offset a higher risk of cognitive impairment for poor sleep quality and/or excessive sleep durations. The associations are similar for both sexes but are stronger in oldest-old adults and differ by urban-rural residence.

\section{Background}

With the rapid population aging, the number of older people with age-related disorders will likely grow, especially people with cognitive impairment, the most common cause of dementia [1,2]. Dementia is considered one of the significant causes of disability among older adults and brings enormous social and financial burdens at both family and societal levels [3]. It is estimated that around 50 million people lived with dementia worldwide in 2015 and the number is projected to increase to 132 million by 2050 [4]. Meanwhile, the dementia cost was as much as US\$ 818 billion in 2015 (1.1\% of the global gross domestic product (GDP), and it is projected to rise to US\$ 2 trillion by $2030[5,6]$. Since there are no effective therapies available for curing dementia by far, early identification of modifiable factors for cognitive impairment and implementation of preventive interventions have become public health priorities $[7,8]$. 
Sleep is a fundamental biobehavioral process that helps to restore functional capacity and maintain both physical and mental health $[9,10]$. Sleep disturbances increase with age. More than half of older adults aged 65 years or older are reported to be poor sleepers [11]. The impacts of sleep problems, such as poor sleep quality $[12,13,14]$ and short or long duration of night-time sleep $[15,16,17]$ and longer and more frequent daytime napping $[18,19]$, on cognitive functioning among older adults have been receiving increasing attention recently. The findings are generally consistent, with the majority of cross-sectional studies having suggested that a short sleep duration (usually 6 hours or less) [20, 21, 22], a long sleep duration (usually 9 hours or more) [23, 24], or both (i.e., a U-shaped relationship or a V-shaped relationship) $[25,26,27,28]$ are linked to an increased risk of cognitive impairment. Some studies have also suggested that poor sleep quality may be linked to an increased risk of cognitive impairment as well. However, a small number of studies have observed no association between sleep hours/quality and cognitive decline [29]. Some longitudinal studies also investigate the association between the extreme sleep durations (short and long sleep durations) at baseline and cognitive decline at follow-up. However, the results were also mixed, with some reporting a positive association whereas others reported no association [30, 31, 32].

The frequent fruit and/or vegetable intake ( $\mathrm{FVI})$ has been shown to improve the overall health condition of older adults by moderating several physical or psychological behaviors, including sleeping patterns $[33,34]$. Experimental evidence has shown that high polyphenol content, melatonin, and serotonin in fruits and vegetables might be beneficial to reducing oxidative stress and improving sleep quality $[35,36]$. It also indicated that plant-based diets are more likely to improve energy metabolism, mitochondrial function, and lower body obesity, which potentially helps older people prevent sleep disorders [37, 38]. Several studies have explored the associations between sleep duration and/or quality and FVI intake among older adults. For example, Noorwali and colleagues found that higher FVI was associated with shorter sleep duration among UK adult women [39]. Several other studies found that compared with daily consumers, people seldom consuming fruits and vegetables had higher odds of reporting poor quality of sleep [33, 34].

However, despite the well-established validity and statistical robustness of sleep duration or quality in predicting cognitive functioning and the known associations between sleep and cognitive impairment [40, 41], it remains largely unknown whether the linkage between sleep and cognitive function varies across different frequencies of intaking fruits and vegetable. Furthermore, it is reasonable to speculate that if the frequency of $\mathrm{FVI}$ is linked to sleep quality and duration, the joint association of sleep duration and quality and the frequency of FVI might be more pronounced for cognitive functioning. Nevertheless, there have been rare to investigate this research question in the existing literature [42].

China is a country that has the largest population of older adults in the contemporary world, with an estimated prevalence of dementia of approximately $6.6 \%$ in 2015-2018 among individuals aged 65 years and older $[43,44,45]$. With the rapid population aging and socio-economic transformation, growing prevalence of unhealthy diets $[46,47,48]$, and sleep disturbance $[49,50,51]$, there is a need to examine how the frequency of $\mathrm{FVI}$ and sleep patterns affect cognitive function among older adults in China. 
Taken together, the current study aims to address the following gaps in the literature. First, though some empirical studies have suggested the extreme sleep duration and poor sleep quality were associated with higher risks of cognitive impairment among Chinese older adults, most of them were based on a small sample from regional surveys (such as Beijing, Guangzhou, or Hebei province, Zhejiang Province) at middle and young older ages $[15,52,53]$. Using a nationally representative panel dataset from mainland China from 2008 to 2011, we aim to investigate the associations between sleep duration and quality and cognitive function, between $\mathrm{FVI}$ and cognitive function, and how sleep duration and quality and $\mathrm{FVI}$ are jointly associated with cognitive function. Second, we aim to examine whether the FVI would moderate the linkage of sleep duration/quality to cognitive impairment and how it varies by gender, age groups, residence area as well as educational attainment.

\section{Methods}

\section{Study population}

The data used in our study were drawn from the 2008 and 2011 waves of the Chinese Longitudinal Healthy Longevity Survey (CLHLS). The CLHLS is an ongoing project in mainland China (thereafter China) and is one of the largest nationally representative longitudinal surveys focused on older adults in the developing world. The first wave of the CLHLS was conducted in 1998, which mainly focused on the oldest-old (aged 80 or older). There have been 9 waves by far. The fieldwork of the ninth wave was just completed in October 2021. The first 8 waves of the CLHLS were conducted in randomly selected half of countries and cities from 22 of 31 provinces in mainland China (plus one county in one of nine notsampled provinces). The survey areas covered nearly 90 percent of the total population of China according to the Sixth National Census in 2010 [54]. The CLHLS was specially designed to interview all centenarians in sampled counties/cities. For non-centenarians, the CLHLS aimed to recruit samples with comparable sizes for ages from 65 to 99 by sex. In other words, CLHLS is not a random sample with an over-sampling of very old adults and men. The information of respondents' socio-demographics, health status, and lifestyles was obtained through in-home interviews with good quality of reliability and validity [55]. The overall response rate for each wave was approximately $90 \%$, and further details of the sampling design and the overall data quality have been provided extensively elsewhere $[55,56]$.

For this study, we focused on respondents aged 65 to 105 years in 2008. Those who reported being 106 or older were excluded because of insufficient information available to validate their extremely old ages [57]. Our final sample included 16,209 respondents in 2008 (see Table 1 for unweighted sample distribution and Appendix Table A1 for weighted distribution). The analytical sample for the incidence of cognitive impairment from 2008 to 2011 was restricted to 7,042 respondents who were cognitively unimpaired. Of other 9,167 respondents, 1,181 respondents (12.88\%) experienced an incidence of cognitive impairment during the three-year interval; 5,401 respondents (58.92\%) died, and 2,585 respondents (28.20\%) were lost to follow-up mainly due to a poor health condition.

\section{Outcome variables}




\section{Cognitive impairment}

Cognitive functioning was measured using the Chinese version of the Mini-Mental State Examination (MMSE), which was adapted from the scale developed by Folstein et al. for less cumbersome and more practical, particularly to older adults and dementia syndromic patients [58]. It contains six segments, namely orientation, registration, attention, calculation, recall, and language, and the total possible score is 30, with a lower score manifesting poor cognitive functioning. The MMSE in Chinese has been used extensively and validated after accurate translation and appropriate modifications in line with the level of education of older adults and other socio-economic or cultural statuses in China [59, 60,61].

The MMSE in this study was classified into two categories: cognition impaired (score <24) and unimpaired (score 24-30) [45, 54, 61]. However, considering the low level of educational attainment among the oldest-old in China, particularly the female older adults in rural areas, an alternative criterion with a score greater than 17 and 20 as cognitively unimpaired being applied to those who never attended school and those who received 1-6 years of schooling, respectively $[62,63,64,65]$.

Unlike other questions in the CLHLS, all MMSE questions must be answered by the sampled persons themselves instead of answering by any proxy (e.g., a spouse or family member). There are some respondents (about 18\% in 2008 and 16\% in 2011) who cannot accomplish the MMSE test due to mental or physical problems (coded as the option 'not able to answer' because of mental impairment and physical illness). Following practice in the literature [66], we coded them as 'wrong'. An alternative approach by coding them as missing values and imputing the missing values produced comparable results. The imputation assumes that the answers to these MMSE questions would be the same if the respondents had the same demographic characteristics, behavioral and psychosocial characteristics, and health conditions (see Appendix Tables A2 and A3). We also excluded these missing values, and the results are comparable to those imputed and those in which "unable to answer" was considered (see Appendix Tables A4 and A5)

\section{Explanatory variables}

\section{Sleep quality and duration}

The 2008 and 2011 waves of the CLHLS included one self-rated question about the global sleep quality: "how do you rate your overall sleep quality recently?" which is similar to Question 6 in the Pittsburgh Sleep Quality Index (PSQI) [67]. The answer contained five categories: very good, good, so so, poor, and very poor. We dichotomized response categories into good (very good/good) versus poor (so so/bad/very bad), with poor as a reference category. Sleep duration was measured by the CLHLS self-rated question: "how long do you sleep normally every day including napping?" According to prior studies, we excluded samples whose self-reported actual sleep duration was abnormal (less than three hours per day) [68]. To gauge possible non-linear associations between sleep duration and cognitive function, we categorized sleep hours into $\leq 6 \mathrm{~h}, 7 \mathrm{~h}, 8 \mathrm{~h}, 9 \mathrm{~h}$, and $\geq 10 \mathrm{~h}$, following the practice in prior studies $[69,70,71,72]$. 


\section{Fruit and vegetable intake}

The CLHLS included self-rated FVI frequency by questions: "how often do you eat fresh fruit nowadays?" and "how often do you eat fresh vegetables nowadays?" Participants having fruits 'every day or almost every day' or 'quite often' or participants having vegetables 'every day or almost every day' were classified into the high frequency of FVI. Participants eating fruits or vegetables 'occasionally' and 'rarely or never' were then encoded as the low frequency. The dichotomization of FVI frequency is to account for its very skewed distribution. Its original ordinal categories were also analyzed as sensitivity tests and the conclusions are similar.

\section{Other covariates}

To obtain robust results, we controlled some confounders that have been proven to be associated with sleep quality and duration in previous studies, as well as those associated with cognitive function [44, 49, 68]. These factors include demographic background, socio-economic status (SES), family and social connections, health practices, and health conditions. The demographic background was comprised of chronological age, gender, ethnicity (Han vs. minority), and the current residence (urban vs. rural). SES was measured by educational attainment ( $1+$ vs. 0 years of schooling), self-reported economic status (higher vs. lower), and adequate access to healthcare (yes vs. no). Family and social connections were measured by marital status (currently married vs. non-married), numbers of children alive, and coresidence with family members (yes vs. no). Health practices were measured by currently smoking (no vs. yes), current alcohol drinking (no vs. yes), and doing regular exercise (yes vs. no). Finally, health condition was measured by self-reported health with three categories (very/good, fair, and poor/very poor).

\section{Analytical strategy}

Three nested logistic regression models were designed to examine associations of sleep quality, sleep duration, and FVI with cognitive impairment, using the data from the 2008 wave. Model I adjusted for demographic variables, including age, gender, ethnicity, and rural-urban residence. Model II additionally incorporated SES, family and social connections, and health practices into the modeling. Model III further adjusted for self-reported health (SRH). One additional model was performed to examine the effects of interactions between $\mathrm{FVI}$ and sleep quality and between $\mathrm{FVI}$ and sleep duration on cognitive impairment after adjusting for other covariates. To order to test the robustness of the associations between FVI, sleep quality and duration, and cognitive impairment, we also applied these designs to subgroups of men and women, young-old and oldest-old adults, and by rural and urban residence.

Similar approaches were applied to the incidence of cognitive impairment modeling by using the cognitive impairment condition in the 2011 wave among 7,042 respondents who were cognitively unimpaired in the 2008 wave (see Appendix Tables A6 and A7). Sensitivity analyses were performed by coding MMSE scores in a logarithm form for the cross-sectional analysis for the 2008 wave (see Appendix Tables A8 and A9) and for the incidence of cognitive function from 2008 and 2011 waves for 
all models (see Appendix Tables A6 and A10). The results are similar, and the conclusions are the same. All analyses were performed using STATA 16.0.

\section{Results}

\section{Sample characteristics}

Table 1 presents the unweighted distribution of the sample characteristics of the 16,209 participants who took part in the baseline study in 2008 (see Table A1 for the weighted results). Most participants were women $(57.19 \%)$, aged 80 or older $(73.56 \%)$ in comparison, and $39.78 \%$ lived in city/town. Nearly threequarters of the participants often consumed fruits and vegetables (73.10\%). Almost two-thirds reported having good sleep quality (65.09\%), and nearly a quarter reported having an 8-hour sleep duration (23.70\%). The mean MMSE score among the participants was $22.26(S D=7.98)$, whereas $26.05 \%$ of the study participants were cognitively impaired in the 2008 wave. Among 7,042 participants who were cognitively unimpaired and survived to the 2011 wave, the mean MMSE score was $24.32(S D=6.97)$ and $16.61 \%$ became cognitively impaired. 
Table 1

Sample distributions of study variables (unweighted)

\begin{tabular}{|c|c|c|c|}
\hline Characteristics & Total & Characteristics & Total \\
\hline Total sample & 16,209 & & \\
\hline Frequency of FVI & & $\%$ Aged 80 or older & 73.56 \\
\hline$\%$ high frequency of $\mathrm{FVI}$ & 73.10 & $\%$ Women & 57.19 \\
\hline Sleep & & $\%$ Han ethnicity & 94.02 \\
\hline$\%$ Good sleep quality & 65.09 & $\%$ Urban & 39.78 \\
\hline$\% \leq 6$ hours of sleep & 26.00 & Socioeconomic Status (SES) & \\
\hline$\% 7$ hours of sleep & 13.01 & $\% 1+$ years of schooling & 37.25 \\
\hline$\% 8$ hours of sleep & 23.70 & $\%$ Economically rich & 13.32 \\
\hline$\% 9$ hours of sleep & 8.33 & $\%$ Adequate access to healthcare & 93.29 \\
\hline$\% \geq 10$ hours of sleep & 28.96 & Family/Social Connections & \\
\hline Cognitive health & & $\%$ Currently married & 31.95 \\
\hline \multirow[t]{2}{*}{ Average MMSE score in 2008 (S.D.) } & 22.26 & \multirow[t]{2}{*}{ Average number of children alive (S.D.) } & 3.63 \\
\hline & $(7.98)$ & & $(1.87)$ \\
\hline \% Cognitively impaired in 2008 & 26.05 & \% Living with family member(s) & 82.62 \\
\hline \multirow[t]{2}{*}{ Average MMSE score in 2011 (S.D.) * } & 24.32 & Health Practice & \\
\hline & $(6.97)$ & $\%$ Not smoking at present & 82.81 \\
\hline$\%$ Cognitively impaired in 2011 * & 16.61 & $\%$ Not drinking at present & 83.05 \\
\hline Demographic Variables & & $\%$ Doing regular exercise & 27.73 \\
\hline \multirow[t]{2}{*}{ Mean age (S.D.) } & 87.05 & Health Condition & \\
\hline & (11.09) & $\%$ Self-reported good health & 43.31 \\
\hline \multicolumn{4}{|c|}{$\begin{array}{l}\text { Note: (1) All variables are measured at the } 2008 \text { wave of baseline unless otherwise stated. (2) High } \\
\text { frequency of fruits and vegetables intakes (FVI) refers to eating fruit and vegetable every day/almost } \\
\text { every day/quite often. (3) Mini-mental Status Examination (MMSE) score, age, and the number of } \\
\text { children alive are measured in mean, whereas all other variables are measured in percentage. (4) * } \\
\text { referring to data among } 7,042 \text { who survived to the } 2011 \text { wave. }\end{array}$} \\
\hline
\end{tabular}

\section{Sleep duration, sleep quality, $\mathrm{FVI}$, and cognitive impairment}

Table 2 presents odds ratios (ORs) in the nested logistic regression models of cognitive impairment for sleep quality, sleep duration, and FVI from cross-sectional analyses using the data of the 2008 wave. 
Model I shows that good sleep quality is associated with a $31 \%$ lower odds of cognitive impairment $(\mathrm{OR}=0.69,95 \% \mathrm{Cl}: 0.63-0.76)$ when only demographic factors plus two other exploratory variables (i.e., sleep duration and $\mathrm{FVI}$ ) were controlled for. The reduction was reduced to $25 \%(\mathrm{OR}=0.75,95 \% \mathrm{Cl}$ : 0.68 $0.83)$ when SES and family and social connection factors were additionally controlled $(p<0.001)$.

However, there was no longer a significant difference when health condition was additionally adjusted for (Model III).

Table 2 also shows that too short $(\leq 6 \mathrm{~h}, \mathrm{OR}=1.15,95 \% \mathrm{Cl}: 1.01-1.31, \mathrm{p}<0.05)$ and too long $(\geq 10 \mathrm{~h}$, $\mathrm{OR}=1.63,95 \% \mathrm{Cl}: 1.46-1.83, \mathrm{p}<0.001)$ sleep duration were both associated with cognitive function impairment compared with $8 \mathrm{~h}$ per day (Model I). The ORs were hardly altered after additionally controlling for SES, family/social support, and health practice $(\leq 6 \mathrm{~h}, \mathrm{OR}=1.17,95 \% \mathrm{Cl}: 1.02-1.33, \mathrm{p}<0.05$; $\geq 10 \mathrm{~h}, \mathrm{OR}=1.62,95 \% \mathrm{Cl}: 1.45-1.82, \mathrm{p}<0.001)$ (Model II). The ORs were slightly reduced to $1.13(95 \% \mathrm{Cl}$ : $0.98-1.29, \mathrm{p}<0.1)$ for $\leq 6 \mathrm{~h}$ and 1.51 (95\% Cl: 1.34-1.70) for $\geq 10 \mathrm{~h}$ when health condition was further adjusted (Model III).

The high frequency of $\mathrm{FVI}$ was associated with a $37 \%$ lower ORs of being cognitively impaired $(\mathrm{OR}=0.63$, $95 \% \mathrm{Cl}: 0.58-0.69)$ when demographics and sleep quality and duration were controlled for (Model I). The OR was mildly attenuated to 0.66 (95\% Cl: $0.61-0.73)$ and 0.71 (95\% Cl: 0.65-0.78) in Models II and III respectively when additional covariates were controlled for $(p<0.001)$. 
Table 2

Unweighted odds ratios of cognitive impairment for study variables, CLHLS, 2008

\begin{tabular}{|c|c|c|c|}
\hline & Model I & Model II & Model III \\
\hline \multicolumn{4}{|l|}{ Sleep quality } \\
\hline Good (fair/poor) & $0.69 * * \star$ & $0.75^{\star \star \star}$ & 0.94 \\
\hline \multicolumn{4}{|l|}{ Sleep duration } \\
\hline$\leq 6$ hours $(8)$ & $1.15^{\star}$ & $1.17 *$ & $1.13+$ \\
\hline 7 hours (8) & 0.97 & 0.99 & 1.06 \\
\hline 9 hours (8) & 1.00 & 1.01 & 1.06 \\
\hline$\geq 10$ hours $(8)$ & $1.63^{\star \star \star}$ & $1.62^{\star \star \star}$ & $1.51^{\star \star \star}$ \\
\hline \multicolumn{4}{|l|}{ Frequency of FVI } \\
\hline High (low) & $0.63^{* * *}$ & $0.66^{\star \star \star}$ & $0.71^{\star \star \star}$ \\
\hline \multicolumn{4}{|l|}{ Covariates } \\
\hline \multicolumn{4}{|l|}{ Demographics } \\
\hline Age & $1.13^{\star \star \star}$ & $1.12^{\star \star \star}$ & $1.12^{\star \star \star}$ \\
\hline Women (men) & $1.45^{\star \star \star}$ & $1.39 * \star \star$ & $1.40 * \star \star$ \\
\hline Han (non-Han minority) & $2.03^{\star \star \star}$ & 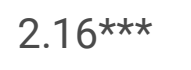 & $1.95^{\star \star \star}$ \\
\hline Urban (rural) & $0.84^{\star \star \star}$ & $0.89 * \star$ & $0.92+$ \\
\hline \multicolumn{4}{|l|}{ Socioeconomic Status (SES) } \\
\hline $1+$ years of schooling $(0)$ & & $1.27 * \star \star$ & $1.34^{\star \star \star}$ \\
\hline Economically rich (fair/poor) & & $0.80 * \star \star$ & 0.90 \\
\hline Adequate access to healthcare (no) & & $0.74 * \star \star$ & $0.84^{\star}$ \\
\hline \multicolumn{4}{|l|}{ Family/Social Connections } \\
\hline Currently married (no) & & $0.81^{\star \star \star}$ & $0.78 * \star \star$ \\
\hline Number of children alive & & 0.99 & 0.99 \\
\hline Living with family member(s) (no) & & $1.43^{\star \star \star}$ & 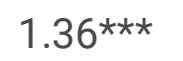 \\
\hline
\end{tabular}

Note: (1) FVI: Fruit and/or vegetable intakes. (2) Cognitive impairment is defined when an MMSE score is less than 18 for the respondents with 0 years of schooling, MMSE score $<21$ for the respondents with 1-6 years of schooling, or MMSE score $<24$ for the respondents with 7+ years of schooling. (3) The category in the parentheses of a variable is the reference group of that variable. (4) ,$+ \mathrm{P}<0.1 ; *, \mathrm{P}<0.05 ; * \star, \mathrm{P}<0.01 ; * \star *, \mathrm{P}<0.001$. 


\begin{tabular}{|c|c|c|c|}
\hline & Model I & Model II & Model III \\
\hline \multicolumn{4}{|l|}{ Health Practices } \\
\hline Not smoking (smoking) & & 1.05 & 1.04 \\
\hline Not alcohol drinking (drinking) & & $1.18 *$ & 1.10 \\
\hline Doing regular exercise (no) & & 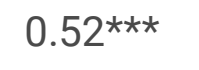 & $0.59 * \star \star$ \\
\hline \multicolumn{4}{|l|}{ Health Condition } \\
\hline Fair self-reported health (poor) & & & $0.33^{\star * \star}$ \\
\hline Good self-reported health (poor) & & & $0.22^{\star \star \star}$ \\
\hline -log likelihood & 7193.2 & 7065.7 & 6619.8 \\
\hline Sample size $(\mathrm{N})$ & 16,209 & 16,209 & 16,209 \\
\hline \multicolumn{4}{|c|}{$\begin{array}{l}\text { Note: (1) FVI: Fruit and/or vegetable intakes. (2) Cognitive impairment is defined when an MMSE } \\
\text { score is less than } 18 \text { for the respondents with } 0 \text { years of schooling, MMSE score } 21 \text { for the } \\
\text { respondents with } 1-6 \text { years of schooling, or MMSE score } 24 \text { for the respondents with } 7+\text { years of } \\
\text { schooling. (3) The category in the parentheses of a variable is the reference group of that variable. (4) } \\
+, P<0.1 ; *, P<0.05 ; * \star, P<0.01 ; * \star \star, P<0.001 \text {. }\end{array}$} \\
\hline
\end{tabular}

\section{Interactions between sleep and FVI}

Table 3 presents ORs for different combinations between sleep quality and FVI and between sleep duration and $\mathrm{FVI}$ after considering all covariates. ORs of cognitive impairment were pronouncedly lower in the categories of good sleep quality plus often FVI (OR=0.65, 95\% Cl: $0.57-0.75, p<0.001)$ and fair/poor sleep quality but often $\mathrm{FVI}(\mathrm{OR}=0.69,95 \% \mathrm{Cl}$ : 0.59-0.79, $\mathrm{p}<0.001)$, respectively, compared with the category of fair/poor sleep quality plus a low frequency of FVI (see Column Total). These associations were consistent between older women and older men, although the association between the category of good sleep quality but not often $\mathrm{FVI}$ and cognitive impairment was marginally stronger in older men $(O R=0.78, p<0.1)$ than in older women $(O R=0.98, p>0.1)$. The results further show that protective effects of often having FVI were more significant in young and urban older adults compared with those in oldestold adults and rural older adults. 
Table 3

Unweighted odds ratios of cognitive impairment in Model IV for the interactions between sleep and FVI, CLHLS, 2008

Total Men Women Young- $\begin{aligned} & \text { Oldest- Rural Urban } \\ & \text { old }\end{aligned}$

Panel A-Sleep quality and FVI

\section{fair/poor plus not often FVI (reference)}

\begin{tabular}{|c|c|c|c|c|c|c|c|}
\hline good but not often FVI & 0.89 & $0.78+$ & 0.97 & 0.69 & 0.92 & 1.10 & $0.58^{\star \star \star}$ \\
\hline fair/poor but often FVI & $0.69 * \star \star$ & $0.70 * \star$ & $0.68^{* \star *}$ & $0.53^{*}$ & $0.70 * \star \star$ & $0.80 *$ & $0.48^{\star \star *}$ \\
\hline good plus often FVI & $0.65^{\star \star \star}$ & $0.66^{\star \star \star}$ & $0.65^{\star \star \star}$ & $0.39 * \star *$ & $0.68^{* \star *}$ & $0.71^{\star \star \star}$ & $0.52^{\star \star \star}$ \\
\hline -log likelihood & 6626.2 & 2379.8 & 4235.4 & 562.3 & 6045.8 & 4131.6 & 2470.9 \\
\hline Sample size $(\mathrm{N})$ & 16,209 & 6,939 & 9,270 & 4,286 & 11,923 & 9,761 & 6,448 \\
\hline
\end{tabular}

Panel B-Sleep hours

and $\mathrm{FVI}$

$\begin{array}{llllllll}\leq 6 \text { hours and not often } & 0.99 & 0.84 & 1.09 & 0.81 & 1.00 & 0.85 & 1.43+\end{array}$

$\mathrm{FVI}$

$\begin{array}{llllllll}7 \text { hours and not often } & 1.12 & 1.14 & 1.10 & 0.71 & 1.17 & 1.05 & 1.32\end{array}$

$\mathrm{FVI}$

\section{8 hours and not often FVI (reference)}

\begin{tabular}{|c|c|c|c|c|c|c|c|}
\hline $\begin{array}{l}9 \text { hours and not often } \\
\text { FVI }\end{array}$ & 1.19 & 1.16 & 1.34 & 1.01 & 1.20 & 1.22 & 1.21 \\
\hline $\begin{array}{l}\geq 10 \text { hours and not } \\
\text { often FVI }\end{array}$ & 1.17 & 1.12 & 1.21 & 1.04 & 1.19 & $1.29+$ & 1.01 \\
\hline$\leq 6$ hours and often FVI & $0.73^{\star *}$ & $0.69 *$ & $0.76^{\star}$ & $0.35^{\star \star}$ & $0.78^{*}$ & $0.73^{\star}$ & 0.76 \\
\hline 7 hours and often FVI & $0.62^{\star \star \star}$ & $0.62^{*}$ & $0.63^{\star * *}$ & $0.21^{\star \star}$ & $0.68^{* * *}$ & $0.55^{\star \star \star}$ & 0.75 \\
\hline 8 hours and often $\mathrm{FVI}$ & $0.61^{\star \star \star}$ & $0.64 *$ & 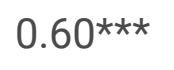 & $0.47^{\star}$ & $0.62^{\star \star \star}$ & $0.63^{\star \star \star}$ & $0.58 * \star$ \\
\hline 9 hours and often $\mathrm{FVI}$ & $0.61^{\star \star \star}$ & $0.62^{\star}$ & $0.60 * \star$ & $0.29 *$ & $0.64^{\star \star \star}$ & $0.52^{\star \star \star}$ & 0.80 \\
\hline $\begin{array}{l}\geq 10 \text { hours and often } \\
\mathrm{FVI}\end{array}$ & 1.03 & 1.18 & 0.97 & 1.20 & 1.03 & 1.04 & 1.04 \\
\hline -log likelihood & 6611.3 & 2371.9 & 4227.2 & 551.4 & 6034.9 & 4116.8 & 2469.4 \\
\hline Sample size $(\mathrm{N})$ & 16,209 & 6,939 & 9,270 & 4,286 & 11,923 & 9,761 & 6,448 \\
\hline
\end{tabular}

Note: (1) Panel A controlled for all covariates in Table 1 plus sleep duration, whereas Panel B controlled for all covariates in Table 1 plus sleep quality. The samples sizes for all models in Panel A are the same as those in Panel B. (2) FVI: fruit and/or vegetable intakes. (3) Bold fonts indicate reference categories of the interaction. (4),$+ \mathrm{P}<0.1 ; *, \mathrm{P}<0.05 ; * \star, \mathrm{P}<0.01 ; * \star \star, P<0.001$. 
With regard to the sleep duration, ORs of cognitive impairment for the high frequency of FVI with short ( $\leq$ $6 \mathrm{~h}, \mathrm{OR}=0.73,95 \% \mathrm{Cl}: 0.60-0.90, \mathrm{p}<0.01)$ or moderate sleep duration $(7 \mathrm{~h}, \mathrm{OR}=0.62,95 \% \mathrm{Cl}: 0.50-0.79 ; 8 \mathrm{~h}$, $\mathrm{OR}=0.61,95 \% \mathrm{Cl}: 0.50-0.75 ; 9 \mathrm{~h}, \mathrm{OR}=0.61,95 \% \mathrm{Cl}: 0.47-0.78)$ were significantly lower compared to the 8hour-sleep with low frequency of FVI among the entire sample $(p<0.001)$. This pattern was similar between older men and older women, although the pattern seemed more pronounced for young and rural older adults. Furthermore, in most sub-population analyses, different sleep hours had no significant relation with cognitive impairment if older adults did not frequently intake fruits or vegetables. Supplementary analyses show that the linkage of sleep quality, sleep duration, and FVI with the incidence of cognitive impairment in a 3-year follow-up period was weak (see Appendix Tables A6 and A7).

\section{Discussion}

This study investigated the independent and joint association of sleep patterns (quality and quantity) and fruits and/or vegetables intake ( $\mathrm{FVI}$ ) with cognitive functioning among old adults in China using the CLHLS. To the best of our knowledge, the present study is among the first to explore the interaction effect of sleep patterns and FVI on cognitive functioning in a relatively large sample.

One major finding is that both poor sleep quality and an extreme sleep duration ( $\leq 6 \mathrm{~h}$ or $\geq 10 \mathrm{~h}$ per day) were associated with cognitive impairment. This finding is in line with several empirical studies. For instance, a systematic review meta-analysis of 11 cross-sectional and 7 prospective cohort studies involving 35 independent samples (total $N=97,264$ ) suggested that both short and long sleep duration were accompanied by a significantly higher risk of developing cognitive impairment among older adults [73]. Studies by Mousavi et al. [12] and Nakakubo et al. [13] also showed that older adults with poor sleep quality had a significantly lower cognitive function and higher prevalence of cognitive impairment than those with good sleep quality.

Our finding between sleep quality, sleep duration, and cognitive impairment is supported by some neurological and pathological hypotheses. First, poor sleep quality is associated with higher rates of cortical atrophy in frontal, temporal, and parietal lobes, which may have adverse effects on cognitive health as shown in some prior studies [73]. Second, as sleep plays a vital role in the clearance of metabolic waste from the brain, insufficient sleep time may have negative effects on the brain [74]. Some experimental studies have demonstrated that sleep deprivation can not only result in neuronal losses in the locus coeruleus [75] but induce pathology of Alzheimer's disease as well by an increased accumulation of amyloid $\beta$ in the brain $[68,76]$. On the other hand, an excessive sleep duration contributes to increases in systemic inflammation disorders [77], such as increases in activities in interleukin-6 (IL-6) and C-reactive protein (CRP) [73, 78], which may have negative effects on brain structure and lead to age-related cognitive impairment [79]. Furthermore, both short sleep ( $\leq 6 \mathrm{~h})$ and long sleep ( $\geq 10 \mathrm{~h}$ ) duration may give rise to brain aging by increasing circadian dysfunction, degenerative disease [19, 80], chronic inflammation [81], and risk of cardiometabolic disease [74, 82]. 
Another important finding is that a higher frequency of FVI turned out to be significantly associated with a lower risk of cognitive impairment, which is in accordance with previous findings [41, 83]. Research has shown that fruits and vegetables contain many antioxidant nutrients and bioactive substances, such as vitamins $A \backslash B \backslash C \backslash E$, zinc, carotenoids, flavonoids, polyphenols [39, 84], phytoestrogens [85, 86], which have been found to prevent the brain from oxidative stresses [83, 87], and thus help to protect against damages of age-related neurologic dysfunction triggered by reactive oxygen species and other free radicals [40]. Additionally, frequent FVI also generates a high fiber intake that positively influences gut microbiota, which might also be linked to better cognitive health [40]. Last but not least, lignin and other phytochemicals such as catechins, L-theanine, and caffeine found in the Chinese diet might also explain the inverse association between FVI and cognitive impairment [41].

Our results also reveal significant associations with cognitive function for the interactions between sleep and FVI. Specifically, compared with older adults reporting poor sleep quality plus the low frequency of $\mathrm{FVI}$, sleep quality plus high FVI frequency (no matter good or poor sleep quality) was associated with a prominently lower risk of cognitive impairment. Furthermore, a high frequency of FVI could offset a higher risk of cognitive impairment for older adults who have a short sleep duration. As abovementioned, both proper sleep patterns and frequent FVI are associated with cognitive function through several biological mechanisms. It is thus reasonable to postulate that the interactions between sleep patterns and FVI could generate a mutually reinforcing effect on cognitive functioning. In addition, it has been shown that the accumulation of proteinaceous amyloid $\beta$ plaques $[76,88]$ and $\tau$ oligomers [89] would occur several years before the onset of serious cognitive impairment [42]. Moreover, poor sleep quality or sleep disorders might negatively affect glymphatic system activity [90], thus giving rise to amyloid accumulation [91]. In such a case, frequent FVI could play an active role in improving cognitive functioning by regulating the proper sleep patterns in that the polyphenol content in fruits and vegetables could alter sleep duration by the gut-brain axis through the improvement of mitochondrial function and energy metabolism in sleep processes, and the antioxidant content of fruits and vegetables might reduce oxidative stress or promote sirtuin 1 (SIRT1) protein expression and thus improve sleep quality [35].

Finally, as the sub-population analyses suggested, the linkages of sleep quality/duration and FVI with cognitive impairment are more pronounced in young older adults compared with those in oldest-old adults. This may be because the incidence of poor sleep, longer sleep duration, and/or cognitive impairment increases sharply with age $[12,92,93]$ that are resulted from age-related deterioration in the homeostatic process, circadian amplitude, thalamocortical and cortico-cortical rhythms (including delta waves, sleep spindles, and slow oscillations) that may be associated with effects of sleep on brain regions $[94,95,96]$. In this circumstance, it is reasonable to infer that the protective effects of $\mathrm{FVI}$ against associations of poor sleep or excessive sleep duration to cognitive impairment are less prominent among the oldest-old adults when they have frequent FVI.

For urban/rural difference in the association between sleep, FVI, and cognitive impairment, the linkage between a longer sleep duration, $\mathrm{FVI}$, and cognitive impairment is more pronounced in rural older adults compared with those in urban older adults, while the linkage between sleep quality, FVI, and cognitive 
impairment seems stronger in urban older adults than in rural older adults. The excessive long sleep duration [96] and the low frequency of FVI [98] have been a concern among rural older adults in China due to their disadvantaged economic/educational statuses, rural lifestyle, and low access to social security and healthcare $[99,100]$. It is thus possible that the adequate sleep duration and the high frequency of FVI could yield greater benefits to cognitive impairment in rural older adults $[50,101,102$, 103]. Consequently, rural older adults are more likely to be sensitive to the improvement of the nutritional status, and the protective effect of FVI on cognitive functioning therefore may be more pronounced for rural adults compared with urban older adults. However, the interaction between good sleep and frequent FVI in linking with cognitive impairment seems more crucial to urban older adults than to rural older adults. There is evidence that the sleep quality of urban older adults in China is a concern due to noises, indoor and outdoor air pollution, shortages of housing, and crowdedness $[104,105,106]$. Therefore, it is reasonable that the positive association of good sleep quality to cognitive function appears more significant among urban older adults than among rural older adults. More research is clearly warranted to shed light on urban-rural differential patterns for sleep duration, sleep quality, and FVI in associating with cognitive function at older or even oldest-old ages.

\section{Implications}

Our findings have several clinical and policy implications. First, public health practitioners are supposed to be aware of the potential adverse prognosis of extreme sleep duration, poor sleep quality, and less FVI might be associated with cognitive impairment risk among older adults [48, 107]. Second, promoting healthy sleep and diet habits (e.g., avoiding excessive time in bed, doing sleep hygiene practices, and promoting dietary plans rich in vegetables and fruits) should be considered in future clinical practices to mitigate cognitive impairment risk $[108,109]$. Third, instead of focusing on regulating older adults' sleeping behaviors directly, more comprehensive and indirect intervention strategies should be designed, such as fruit and vegetable dietary therapies to reduce sleep-related cognitive impairment risk [34, 42]. Moreover, further research should define intervention strategies and provide more specific recommendations to implement preventative and therapeutic strategies. Last but not least, it would be interesting to investigate possible biological mechanisms underlying the linkage between the interaction of sleep and FVI to cognitive functioning among older adults. These implications are important for policymaking and interventions to promote healthy aging considering the enlarging number of older adults who are not only at a higher risk of developing cognitive disorders but particularly vulnerable to sleeping problems in the coming decades.

\section{Limitations}

When interpreting our findings, the following shortcomings should be taken into account. First, similar to most epidemiological studies, information on the sleep duration in the CLHLS was obtained from a selfreported single-item measure that used hourly categories as a response for sake of the lower cost and easiness of administration. Thus, the recall errors cannot be fully excluded [110]. Nevertheless, such biases should not be substantial as several prior validation studies have found that the self-reported 
sleep duration is usually well compared with sleep durations based on polysomnography or actigraphy [111]. Second, information of respondents' sleep duration in the CLHLS did not explicitly ask participants to differentiate daytime napping from the night sleep amount. Studies have shown that the sleep patterns of daytime napping may be different from that of sleep overnight and may have independent and different effects on cognitive functioning [27]. However, some empirical evidence has suggested that daytime napping and nocturnal sleep may share similar mechanisms underlying their associations with cognitive functioning [112], thus it may not be a serious issue to apply the daytime and nighttime combined sleep duration in research. Third, measures on FVI in the CLHLS were relatively coarse, relying on two single items regarding consumption frequency of fruits and vegetables and did not have more specific information on consumption amount or types of fruits and vegetables, which would be subject to some biases [110]. Though self-reported bias is a common limitation in most survey-based research, future research should use more rigorous data collection methods to capture FVI patterns [34]. Last but not least, due to the complexity and dynamics between sleep patterns and cognitive function, we are not able to disentangle whether sleep altered the risk of cognitive impairment or different cognitive performance resulted in variation of sleep. We welcome more research to shed light on this issue.

\section{Conclusions}

The results of this study indicate that good sleep quality, appropriate sleep duration, and FVI are associated with a lower risk of cognitive impairment. More notably, FVI could offset the higher risk of cognitive impairment for poor sleep quality and/or excessive sleep durations. However, these associations are mostly cross-sectional or cumulative. The associations are similar for both sexes but are stronger in young older adults and differ by urban-rural residence.

\section{Abbreviations}

FVI: Fruit and/or Vegetable Intake; CLHLS: Chinese Longitudinal Healthy Longevity Survey; MMSE: Minimental State Examination; PSQI: Pittsburgh Sleep Quality Index; ORs: odds ratios; SD: standard deviation; Cl: confidence interval.

\section{Declarations}

\section{Ethics approval and consent to participate}

No ethics approval was required for the dataset used in this study. The Chinese Longitudinal Healthy Longevity Survey (CLHLS) is a publicly available dataset.

\section{Consent for publication}

Not applicable.

\section{Availability of data and material}


The Chinese Longitudinal Healthy Longevity Survey (CLHLS) was jointly implemented by the Aging Center of Duke University and the Center for Healthy Aging and Family Studies (CHAFS), Peking University. The datasets and questionnaires are publicly available (https://sites.duke.edu/centerforaging/programs/chinese-longitudinal-healthy-longevity-survey-clhls/).

\section{Competing interests}

DG is a Senior Editorial Board Member of the Journal.

\section{Funding}

CB's work is supported by the National Natural Science Foundation of China (No. 72104240) and the Scientific Research Foundation of Renmin University of China (No. 21XNA013).

\section{Authors' contributions}

$\mathrm{CB}$ and $\mathrm{YX}$ contributed equally. $\mathrm{CB}$ drafted the manuscript, interpreted the results, and co-designed the research. YX prepared data, performed the analyses, and drafted the methods and results. DG designed, drafted some parts of the manuscript, and revised the entire paper. DG also supervised the data analysis and is responsible for the accuracy of the results. All authors read and approved the final version of the manuscript.

\section{Acknowledgments}

Not applicable.

\section{References}

1. Prince M, Bryce R, Albanese E, Wimo A, Ribeiro W, Ferri CP. The global prevalence of dementia: a systematic review and meta-analysis. Alzheimer's \& Dementia. 2013;9(1): 63-75(e62). https://doi.10.1016/j.jalz.2012.11.007.

2. Prince M, Comas-Herrera A, Knapp M, Guerchet M, Karagiannidou M. World Alzheimer Report 2016. Improving healthcare for people with dementia: coverage quality and costs now and in the future. Alzheimer' s Disease International. https://www.alzint.org/u/WorldAlzheimerReport2016.pdf.

3. Rashmita B. Dementia caregiving, care recipient health, and financial burdens. Innovation in Aging. 2020;4, 56. http://doi.org/10.1093/geroni/igaa057.183.

4. WHO. Global action plan on the public health response to dementia 2017-2025. 2017; https://apps.who.int/iris/handle/10665/259615.

5. Prince M, Wimo A, Guerchet M, Ali GC, Prina M. World Alzheimer Report 2015. The global impact of dementia: An analysis of prevalence, incidence, cost and trends. Alzheimer' s Disease International. https://www.alz.co.uk/research/WorldAlzheimerReport 2015.pdf. 
6. WHO. Risk reduction of cognitive decline and dementia-WHO Guidelines. 2019; https://apps.who.int/iris/bitstream/handle/10665/312180/9789241550543-eng.pdf?ua=1.

7. Frankish $\mathrm{H}$, Horton R. Prevention and management of dementia: A priority for public health. Lancet. 2017;390(10113), 2614-5. http://doi.org/10.1016/S0140-6736(17)31756-7.

8. Livingston G, Sommerlad A, Orgeta V, Costafreda SG, Mukadam N. Dementia prevention, intervention, and care. Lancet. 2017;390(10113), 2673-734. http://doi.org/10.1016/S0140-6736(17)31363-6.

9. Dolgin E. Deprivation: A wake-up call. Nature. 2013;497(7450), S6-S7. http://doi.org/10.1038/497S6a.

10. Hallit S, Hajj A, Sacre H, Karaki GA, Malaeb D, Kheir N, Salameh P, Hallit R. Impact of sleep disorders and other factors on the quality of life in general population: A cross-sectional study. The Journal of Nervous and Mental Disease. 2109;207(5), 333-9. http://doi.org/10.1097/NMD.0000000000000968.

11. Ancoli-Israel S, Martin JL. Insomnia and daytime napping in older adults. Journal of clinical sleep medicine. 2006;2(3), 333-42. http://doi.org/10.5664/jcsm.26597.

12. Mousavi SV, Montazar E, Rezaei S, Hosseini SP. Sleep quality and cognitive function in the elderly population. Journal of Sleep Research. 2020;5(1), 20-7. http://doi.org/10.18502/jss.v5i1.4569.

13. Nakakubo S, Makizako H, Doi T, Tsutsumimoto K, Lee S, Lee S, Hotta R, Bae S, Suzuki T, Shimada H. Impact of poor sleep quality and physical inactivity on cognitive function in community-dwelling older adults. Geriatrics \& Gerontology International. 2017;17(11), 1823-8. http://doi.org/10.1111/ggi.12973.

14. Sutter C, Zöllig J, Allemand M, Martin, M. Sleep quality and cognitive function in healthy old age: The moderating role of subclinical depression. Neuropsychology. 2012;26(6), 768-75. http://doi.org/10.1037/a0030033.

15. Ding G, Li J, Lian Z. Both short and long sleep durations are associated with cognitive impairment among community-dwelling Chinese older adults. Medicine. 2020;99(13), e19667. http://doi.org/10.1097/MD.0000000000019667.

16. Nazar G, María Leiva A, Troncoso C, Martínez A, Petermann-Rocha F, Villagrán M, Mardones L, Martorell M, María Labraña A, Ulloa N, Díaz-Martínez X, Poblete-Valderrama F, Garrido-Méndez A, Celis-Morales $\mathrm{C}$. Association between sleep duration and cognitive impairment in older people. Revista Medica De Chile. 2019147(11), 1398-406. http://doi.org/10.4067/S003498872019001101398.

17. Zhu Q, Fan H, Zhang X, Ji C, Xia Y. Changes in sleep duration and 3-year risk of mild cognitive impairment in Chinese older adults. Aging. 2020;11(1), 309-17. http://doi.org/10.18632/aging.102616.

18. Cross N, Terpening Z, Rogers NL, Duffy SL, Hickie IB, Lewis SJG, Naismith SL. Napping in older people 'at risk' of dementia: Relationships with depression, cognition, medical burden and sleep quality. Journal of Sleep Research. 2015; 24(5), 494-502. http://doi.org/10.1111/jsr.12313.

19. Leng Y, Redline S, Stone KL, Ancoli-Israel S, Yaffe K. Objective napping, cognitive decline, and risk of cognitive impairment in older men. Alzheimer's \& Dementia. 2019;15(8), 1039-47. 
http://doi.org/10.1016/j.jalz.2019.04.009.

20. Ohayon MM, Vecchierini MF. Daytime sleepiness and cognitive impairment in the elderly population. Archives of Internal Medicine. 2002;162(2), 201-8. http://doi.org/10.1001/archinte.162.2.201.

21. Ohayon MM, Vecchierini MF. Normative sleep data, cognitive function and daily living activities in older adults in the community. Sleep. 2005;28(8), 981-9. http://doi.org/10.1093/sleep/28.8.981.

22. Tworoger SS, Lee S, Schernhammer ES, Grodstein F. The association of self-reported sleep duration, difficulty sleeping, and snoring with cognitive function in older women. Alzheimer Disease and Associated Disorders. 2006;20(1), 41-8. http://doi.org/10.1097/01.wad.0000201850.52707.80.

23. Kronholm E, Sallinen M, Suutama T, Sulkava R, Era P, Partonen T. Self-reported sleep duration and cognitive functioning in the general population. Journal of Sleep Research. 2010;18(4), 436-46. http://doi.org/10.1111/j.1365-2869.2009.00765.x.

24. Schmutte T, Harris S, Levin R, Zweig R, Katz M, Lipton R. The relation between cognitive functioning and self-reported sleep complaints in nondemented older adults: Results from the Bronx Aging Study. Behavioral Sleep Medicine. 2007;5(1), 39-56. http://doi.org/10.1080/15402000709336725.

25. Fauble R, López-Gracía E, Guallar-Castillón P, Graciani A, Banegas JR, Rodríguez-Artalejo F. Usual sleep duration and cognitive function in older adults in Spain. Journal of Sleep Research. 2009;18(4), 427-35. http://doi.org/10.1111/j.1365-2869.2009.00759.x.

26. Ramos AR, Dong C, Elkind MSV, Boden-Albala B, Sacco RL, Rundek T, Wright CB. Association between sleep duration and the Mini-Mental Score: The Northern Manhattan Study. Journal of clinical sleep medicine. 2013;9(7), 669-73. http://doi.org/10.5664/jcsm.2834.

27. Wu L, Sun D, Tan Y. A systematic review and dose-response meta-analysis of sleep duration and the occurrence of cognitive disorders. Sleep and Breathing. 2018;22(3), 805-14. http://doi.org/10.1007/s11325-017-1527-0.

28. Xu L, Jiang C, Hing L, Liu B, Jin Y, Zhu T, Zhang W, Cheng K, Thomas GN. Short or long sleep duration is associated with memory impairment in older Chinese: The Guangzhou Biobank Cohort Study. Sleep. 2011;34(5), 575-80. http://doi.org/10.1093/sleep/34.5.575.

29. Luik Al, Zuurbier LA, Hofman A, Someren EV, Ikram MA, Tiemeier H. Associations of the 24-hour activity rhythm and sleep with cognition: A population-based study of middle-aged and elderly persons. Sleep Medicine. 2015;16(7), 850-5. http://doi.org/10.1016/j.sleep.2015.03.012.

30. Devore EE, Grodstein F, Duffy JF, Stampfer MJ, Czeisler CA, Schernhammer ES. Sleep duration in midlife and later life in relation to cognition. Journal of the American Geriatrics Society. 2014;62(6), 1073-81. http://doi.org/10.1111/jgs.12790.

31. Keage HAD, Banks S, Yang KL, Morgan K, Brayne C, Matthews FE. What sleep characteristics predict cognitive decline in the elderly? Sleep Medicine. 2012;13(7), 886-92. http://doi.org/10.1016/j.sleep.2012.02.003.

32. Potvin $\mathrm{O}$, Lorrain D, Dubé M, Grenier S, Préville M, Hudon C. Sleep quality and 1-year incident cognitive impairment in community-dwelling older adults. Sleep. 2012;35(4), 491-9. http://doi.org/10.5665/sleep.1732. 
33. Fan H, Lee YH, Chang Y, Shelley M. Associations of dietary habits and sleep in older adults: A 9-year follow-up cohort study. European Geriatric Medicine. 2021;12(1), 123-31. http://doi.org/10.1007/s41999-020-00377-0.

34. Lee YH, Chang Y, Lee YT, Shelley M, Liu C. Dietary patterns with fresh fruits and vegetables consumption and quality of sleep among older adults in mainland China. Sleep and Biological Rhythms. 2018;16(3), 293-305. http://doi.org/10.1007/s41105-018-0163-9.

35. Noorwali E, Hardie L, Cade J. Bridging the reciprocal gap between sleep and fruit and vegetable consumption: A review of the evidence, potential mechanisms, implications, and directions for future work. Nutrients. 2019;11(6), 1382-427. http://doi.org/10.3390/nu11061382.

36. Peuhkuri K, Sihvola N, Korpela R. Diet promotes sleep duration and quality. Nutrition Research. 2012;32(5), 309-19. http://doi.org/10.1016/j.nutres.2012.03.009.

37. Svendsen M, Blomhoff R, Holme I, Tonstad S. The effect of an increased intake of vegetables and fruit on weight loss, blood pressure and antioxidant defense in subjects with sleep related breathing disorders. European Journal of Clinical Nutrition. 2006;61, 1301-11. http://doi.org/10.1038/sj.ejcn.1602652.

38. Wang M, Shi T, Li Q, Chen H, Liu M, Lu Y, He Q, Chen R. Associations of sleep duration and fruit and vegetable intake with the risk of metabolic syndrome in Chinese adults. Medicine. 2021;100(10), e24600. http://doi.org/10.1097/MD.0000000000024600.

39. Noorwali E, Hardie L, Cade J. Fruit and vegetable consumption and their polyphenol content are inversely associated with sleep duration: Prospective associations from the UK women's cohort study. Nutrients. 2018;10(11), 1803. http://doi.org/10.3390/nu10111803.

40. Gehlich KH, Beller J, Lange-Asschenfeldt B, Köcher W, Meinke MC, Lademann J. Consumption of fruits and vegetables: Improved physical health, mental health, physical functioning and cognitive health in older adults from 11 European countries. Aging and Mental Health. 2020;24(4), 634-41. http://doi.org/10.1080/13607863.2019.1571011.

41. Mottaghi T, Amirabdollahian F, Haghighatdoost F. Fruit and vegetable intake and cognitive impairment: A systematic review and meta-analysis of observational studies. European Journal of Clinical Nutrition. 2018;72(10), 1336-44. http://doi.org/10.1038/s41430-017-0005-x.

42. Pistollato F, Cano SS, Elio I, Vergara MM, Giampieri F, Battino M, Sumalla Cano S, Masias Vergara M. Associations between sleep, cortisol regulation, and diet: Possible implications for the risk of Alzheimer disease. Advances in Nutrition. 2016;7(4), 679-89. http://doi.org/10.3945/an.115.011775.

43. Jia L, Quan M, Fu Y, Zhao T, Li Y, Wei C, Tang Y, Qin Q, Wang F, Qiao Y, Shi S, Wang Y, Du Y, Zhang J, Zhang J, Luo B, Qu Q, Zhou C, Gauthier S, Jia J. Dementia in China: Epidemiology, clinical management, and research advances. The Lancet Neurology. 2020;19(1), 81-92. http://doi.org/10.1016/S1474-4422(19)30290-X.

44. Maree SBC, Mario S. Determining risk of dementia: A look at China and beyond. Age and Ageing. 2020;49(5), 427-8. http://doi.org/10.1093/ageing/afaa130. 
45. Wang R, Feng Q, Dupre ME, Guo A, Qiu L, Hao L, Zhao Y, Gu D. Objective and subjective financial status and mortality among older adults in China. Archives of Gerontology and Geriatrics. 2019;81, 182-91. http://doi.org/10.1016/j.archger.2018.12.006.

46. Dong L, Xiao R, Cai C, Xu Z, Wang S, Pan L, Yuan L. Diet, lifestyle and cognitive function in old Chinese adults. Archives of Gerontology and Geriatrics. 2016;63, 36-42. http://doi.org/10.1016/j.archger.2015.12.003.

47. Gu D, Feng Q, Chen H, Zeng Y. Chinese Longitudinal Healthy Longevity Study in D. Gu and M. E. Dupre (eds). Encyclopedia of Gerontology and Population Aging. 2021; http://doi.org/10.1007/978-3319-69892-2_968-1.

48. Li Y, Jiang B, Zhang M, Huang Z, Deng Q, Zhou M, Zhao Z, Wang Y, Wang L. Vegetable and fruit consumption among Chinese adults and associated factors: A nationally representative study of 170,847 adults. Biomedical and Environmental Sciences. 2017;30(12), 863-74. http://doi.org/10.3967/bes2017.117.

49. Lauriola M, Esposito R, Zambotti MD, Ondrillo F, Rabinovici GD, Kramer J, Tartaro A. Disrupted Sleep in Subjective Cognitive Decline. Alzheimer's and Dementia 2016;12, 230-1. http://doi.org/10.1016/j.jalz.2016.06.414.

50. Xie L, Yang B, Liao Y, Gao G, Richmond CJ. Sleep disturbance in older adults with or without mild cognitive impairment and its associated factors residing in rural area, China. Journal of Geriatric Psychiatry and Neurology. 2020; 1-10. http://doi.org/10.1177/0891988720964249.

51. Ye B, Zhu Y, Wang X, Wei S, Liang Y. Association between sleep-wake habits and use of health care services of middle-aged and elderly adults in China. Aging. 2020;12(4), 3926-35. http://doi.org/10.18632/aging.102860.

52. Lin J, Li F, Chen X, He F, Zhai Y, Pan X, Wang X, Zhang T, Yu M. Association of postlunch napping duration and night-time sleep duration with cognitive impairment in Chinese elderly: A crosssectional study. BMJ Open. 2018;8(12), e023188. http://doi.org/10.1136/bmjopen-2018-023188.

53. Song Q, Liu X, Hu W, Han X, Zhou W, Lu A, Wang X, Wu S. Night sleep duration and risk of cognitive impairment in a Chinese population: a cross-sectional study. Biomedical and Environmental Sciences. 2017;30(10), 749-57. http://doi.org/CNKI:SUN:SWYX.0.2017-10-006.

54. Gu D, Brown BL, Qiu L. Self-perceived uselessness is associated with lower likelihood of successful aging among older adults in China. BMC Geriatrics. 2016;16(172), 1-12. http://doi.org/10.1186/s12877-016-0348-5.

55. Zeng Y. Reliability of age reporting among the Chinese oldest-old in the CLHLS datasets. Healthy Longevity in China. 2008; 20, 61-78. http://doi.org/10.1007/978-1-4020-6752-5_4.

56. Gu Y, He Y, Shahmir H, Kaitlyn H, Dong H, Gittelsohn J. Fruit and vegetable intake and all-cause mortality in a Chinese population: The China Health and Nutrition Survey. International Journal of Environmental Research and Public Health. 2021;18(1), E342. http://doi.org/10.3390/ijerph18010342. 
57. Zeng Y, Vaupel JW, Xiao Z, Zhang C, Liu Y. Sociodemographic and health profiles of the oldest old in China. Population and Development Review. 2002;28(2), 251-73. http://doi.org/10.1111/j.17284457.2002.00251.x.

58. Folstein MF, Folstein SE, Mchugh PR. "Mini-Mental State": A practical method for grading the cognitive state of patients for the clinician. Journal of Psychiatric Research. 1975;12(3), 189-8. http://doi.org/10.1016/0022-3956(75)90026-6.

59. Yu E, Liu W, Levy P, Zhang M, Katzman R, Lung CT, Wong S, Wang Z, Qu G. Cognitive impairment among elderly adults in Shanghai, China. Journal of Gerontology. 1989;44(3), S97-S106. http://doi.org/10.1093/geronj/44.3.S97.

60. Zhang Z. Gender differentials in cognitive impairment and decline of the oldest old in China. The Journals of Gerontology, Series B: Psychological Sciences and Social Sciences. 2020;61(2), S107S115. http://doi.org/10.1093/geronb/61.2.S107.

61. Yang F, Gu D. Predictors of loneliness incidence in Chinese older adults from a life course perspective: A national longitudinal study. Aging \& Mental Health. 2020;24(6), 879-88. http://doi.org/10.1080/13607863.2018.1558174.

62. Hao L, Xu X, Dupre ME, Guo A, Zhang X, Qiu L, Zhao Y, Gu D. Adequate access to healthcare and added life expectancy among older adults in China. BMC Geriatrics. 2020;20(1), 129-43. http://doi.org/10.1186/s12877-020-01524-9.

63. Zeng Y, Chen HS, Ni T, Ruan RP, Feng L, Nie C, Cheng LG, Li Y, Tao W, Gu J. GxE Interactions between FOXO Genotypes and Tea Drinking Are Significantly Associated with Cognitive Disability at Advanced Ages in China. Journals of Gerontology. Series A, Biological Sciences \& Medical Sciences. 2015;70(4), 426-33. http://doi.org/10.1093/gerona/glu060.

64. Zhang Z, Gu D, Hayward MD. Childhood nutritional deprivation and cognitive impairment among older Chinese people. Social Science \& Medicine. 2010;71(5), 941-9. http://doi.org/10.1016/j.socscimed.2010.05.013.

65. Zhao Y, Xu X, Dupre ME, Xie Q, Qiu L, Gu D. Individual-level factors attributable to urban-rural disparity in mortality among older adults in China. BMC Public Health. 2020;20(1), 1472. http://doi.org/10.1186/s12889-020-09574-9.

66. Zeng Y, Feng Q, Gu D, Vaupel JW. Demographics, phenotypic health characteristics and genetic analysis of centenarians in China. Mechanisms of Ageing and Development. 2017;165, 86-97. http://doi.org/10.1016/j.mad.2016.12.010.

67. Buysse DJ, Reynolds CF, Monk TH, Berman SR, Kupfer DJ. The Pittsburgh Sleep Quality Index: a new instrument for psychiatric practice and research. Psychiatry Research. 1989;28(2), 193-213. http://doi.org/10.1016/0165-1781(89)90047-4.

68. Basta M, Simos P, Vgontzas A, Koutentaki E, Tziraki S, Zaganas I, Panagiotakis S, Kapetanaki S, Fountoulakis N, Lionis $\mathrm{C}$. Associations between sleep duration and cognitive impairment in mild cognitive impairment. Journal of Sleep Research. 2019;28(6), e12864. http://doi.org/10.1111/jsr.12864. 
69. Gallicchio L, Kalesan B. Sleep duration and mortality: A systematic review and meta-analysis. Journal of Sleep Research. 2009;18(2), 148-58. http://doi.org/10.1111/j.1365-2869.2008.00732.x.

70. Gu D, Sautter J, Pipkin R, Zeng Y. Sociodemographic and health correlates of sleep quality and duration among very old Chinese. Sleep. 2010;33(5), 601-10. http://doi.org/10.1093/sleep/33.5.601.

71. Malek-Ahmadi M, Kora K, O'Connor K, Schofield S, Coon D, Nieri W. Longer self-reported sleep duration is associated with decreased performance on the montreal cognitive assessment in older adults. Aging Clinical and Experimental Research. 2016;28(2), 333-7. http://doi.org/10.1007/s40520015-0388-2.

72. Chen C, Liu G, Sun Y, Gu D, Zhang H, Yang H, Lu L, Zhao Y, Yao Y. Association between household fuel use and sleep quality in the oldest-old: Evidence from a propensity-score matched case-control study in Hainan, China. Environmental Research. 2020;191(886), 110229. http://doi.org/10.1016/j.envres.2020.110229.

73. Lo JC, Groeger JA, Cheng G, Dijk DJ, Chee MWL. Self-reported sleep duration and cognitive performance in older adults: A systematic review and meta-analysis. Sleep Medicine. 2016;17(4), 8798. http://doi.org/10.1016/j.sleep.2015.08.021.

74. Wu J, Cheng H, Sheng L, Feng L, Yuan J, Michael C, Pan A, Woon-Puay K. Prospective associations between change in sleep duration and cognitive impairment: Findings from the Singapore Chinese Health Study. Journal of Affective Disorders. 2021;281, 125-30. http://doi.org/10.1016/j.jad.2020.12.007.

75. Zhang J, Zhu Y, Zhan G, Fenik P, Panossian L, Wang M, Reid S, Lai D, Davis JG, Baur JA. Extended wakefulness: Compromised metabolics in and degeneration of locus ceruleus neurons. Journal of Neuroscience. 2014;34(12), 4418-31. http://doi.org/10.1523/JNEUROSCI.5025-12.2014.

76. Liang Y, Qu L, Liu H. Non-linear associations between sleep duration and the risks of mild cognitive impairment/dementia and cognitive decline: A dose-response meta-analysis of observational studies. Aging Clinical and Experimental Research. 2019;31(3), 309-20. http://doi.org/10.1007/s40520-018-1005-y.

77. Kondo R, Miyano I, Lee S, Shimada H, Kitaoka H. Association between self-reported night sleep duration and cognitive function among older adults with intact global cognition. International Journal of Geriatric Psychiatry. 2020;36(5), 766-74. http://doi.org/10.1002/gps.5476.

78. Satizabal CL, Zhu YC, Mazoyer B, Dufouil C, Tzourio C. Circulating IL-6 and CRP are associated with MRI findings in the elderly: The 3C-Dijon Study. Neurology. 2012;78(10), 720-7. http://doi.org/10.1212/WNL.0b013e318248e50f.

79. Ma Y, Liang L, Zheng F, Shi L, Zhong B, Xie W. Association between sleep duration and cognitive decline. JAMA Network Open. 2020;3(9), e2013573. http://doi.org/10.1001/jamanetworkopen.2020.13573.

80. Yaffe K, Falvey CM, Hoang T. Connections between sleep and cognition in older adults. Lancet Neurology. 2014;13(10), 1017-28. http://doi.org/10.1016/S1474-4422(14)70172-3. 
81. Patel SR, Zhu X, Storfer-Isser A, Mehra R, Jenny NS, Russell T, Redline S. Sleep duration and biomarkers of inflammation. Sleep. 2009;32(2), 200-4. http://doi.org/10.1093/sleep/32.2.200.

82. Cappuccio FP, Cooper D, Delia L, Strazzullo P, Miller MA. Sleep duration predicts cardiovascular outcomes: A systematic review and meta-analysis of prospective studies. European Heart Journal. 2011;32(12), 1484-92. http://doi.org/10.1093/eurheartj/ehr007.

83. Wu L, Sun D, Tan Y. Intake of fruit and vegetables and the incident risk of cognitive disorders: A systematic review and meta-analysis of cohort studies. The Journal of Nutrition Health and Aging. 2017;21(10), 1284-90. http://doi.org/10.1007/s12603-017-0875-6.

84. Jang S, Panicka, KS. Dietary and plant polyphenols exert neuroprotective effects and improve cognitive function in Cerebral Ischemia. Recent Patents on Food Nutrition \& Agriculture. 2013;5(2), 128-43. http://doi.org/10.2174/1876142911305020003.

85. Soni M, Rahardjo TBW, Soekardi R, Sulistyowati Y, Hogervorst E. Phytoestrogens and cognitive function: A review. Maturitas. 2014;77(3), 209-20. http://doi.org/10.1016/j.maturitas.2013.12.010.

86. Zaw JTJ, Howe PRC, Wong RHX. Does phytoestrogen supplementation improve cognition in humans? A systematic review. Annals of the New York Academy of Sciences. 20171403(1), 150-63. http://doi.org/10.1111/nyas.1345.

87. Yuan C, Fondell E, Bhushan A, Ascherio A, Willett WC. Long-term intake of vegetables and fruits and subjective cognitive function in US men. Neurology. 2018;92(1), e63-e75. http://doi.org/10.1212/WNL.0000000000006684.

88. Kang JE, Lim MM, Bateman RJ, Lee JJ, Smyth LP, Cirrito JR, Fujiki N, Nishino S, Holtzman DM. Amyloid-beta dynamics are regulated by orexin and the sleep-wake cycle. Science. 2009;326(5955), 1005-7. http://doi.org/10.1126/science.1180962.

89. Mroczko B, Groblewska M, Litman-Zawadzka A. The role of protein misfolding and tau oligomers (TauOs) in Alzheimer's disease (AD). International Journal of Molecular Sciences. 2019;20(19), 4661. http://doi.org/10.3390/ijms20194661.

90. Hauglund NL, Pavan C, Nedergaard M. Cleaning the sleeping brain-the potential restorative function of the glymphatic system. Current Opinion in Physiology. 2020;15, 1-6. http://doi.org/10.1016/j.cophys.2019.10.020.

91. Oliver $\mathrm{CR}$, Ysbrand D. The sleeping brain: Harnessing the power of the glymphatic system through lifestyle choices. Brain Sciences. 2020;10(11), E868. http://doi.org/10.3390/brainsci10110868.

92. Lovro Š, Vlatko V, Goran V, Goran S. Sleep Duration and Sleep Quality as Predictors of Health in Elderly Individuals. Sustainability. 2018;10(11), 3918. http://doi.org/10.3390/su10113918.

93. Tel $\mathrm{H}$. European Psychiatry. The quality of sleep and the quality of life among the elderly people. 2011;26, 405. http://doi.org/10.1016/S0924-9338(11)72113-7.

94. Alhola P, Polo-Kantola P. Sleep deprivation: Impact on cognitive performance. Neuropsychiatric Disease and Treatment. 2007;3(5), 553-67. http://europepmc.org/backend/ptpmcrender.fcgi? accid=PMC2656292\&blobtype=pdf. 
95. Cajochen C, Munch M, Knoblauch V, Blatter K, Wirz-Justice A. Age-related changes in the circadian and homeostatic regulation of human sleep. Chronobiology International. 2006;23(1-2), 461-74. http://doi.org/10.1080/07420520500545813.

96. Marshall L, Born J. The contribution of sleep to hippocampus-dependent memory consolidation. Trends in cognitive sciences. 2007;11(10), 442-50. http://doi.org/10.1016/j.tics.2007.09.001.

97. Lu L, Wang S, Rao W, Ng CH, Chiu HFK, Zhang J, Kou C, Jia F, Xiang Y. Sleep duration and patterns in Chinese older adults: a comprehensive meta-analysis. International journal of biological sciences. 2017;13(6), 682-9. http://doi.org/10.7150/ijbs.19695.

98. Yin Z, Chen J, Zhang J, Ren Z, Dong K, Kraus VB, Wang ZQ, Zhang M, Zhai Y, Song P. Dietary patterns associated with cognitive function among the older people in underdeveloped regions: Finding from the NCDFaC Study. Nutrients. 2018;10(4), 464. http://doi.org/10.3390/nu10040464.

99. Grandner MA, Patel NP, Gehrman PR, Xie D, Sha D, Weaver T. Who gets the best sleep? Ethnic and socioeconomic factors related to sleep complaints. Sleep Medicine. 2010;11(5), 470-8. http://doi.org/10.1016/j.sleep.2009.10.006.

100. Wang K, Zhang X, Yi L, Hang W, Sun B, Zhou Z. Self-rated sleep status and related factors among people aged 65 years and over in Yiling rural mountainous area. South China Journal of Preventive Medicine. 2015;41(5), 419-23. http://doi.org/10.13217/j.scjpm.2015.0419.

101. Ji X, Fu Y. The role of sleep disturbances in cognitive function and depressive symptoms among community-dwelling elderly with sleep complaints. International Journal of Geriatric Psychiatry. 2021;36(1), 96-105. http://doi.org/10.1002/gps.5401.

102. Liu R, Tang S, Wang Y, Dong Y, Hou T, Ren Y, Qin Y, Cong L, Qiu C, Du Y. Associations of sleep characteristics with mild cognitive impairment and dementia among Chinese elderly people living in a rural area: A population-based study. Alzheimer's \& Dementia. 2020;16, e042382. http://doi.org/10.1002/alz.042382.

103. Silbert LC, Wall RC, Zachary B, Hiroko D, Nora M, Thomas R, Miranda L, Jeffrey K. Sleep duration and its association with cognition vary with rurality in older veterans. Alzheimer's and Dementia. 2020;16. http://doi.org/10.1002/alz.046482.

104. Tang M, Li D, Liew Z, Wei F, Wang J, Jin M, Chen K, Ritz B. The association of short-term effects of air pollution and sleep disorders among elderly residents in China. The Science of the total environment. 2020;708, 134846. http://doi.org/10.1016/j.scitotenv.2019.134846.

105. Xu X, Lan L, Shen J, Sun Y, Lian Z. Five hypotheses concerned with bedroom environment and sleep quality: A questionnaire survey in Shanghai city, China. Building and Environment. 2021;205(108252), 1-11. http://doi.org/10.1016/j.buildenv.2021.108252.

106. Xu X, Lian Z, Shen J, Lan L, Sun Y. Environmental factors affecting sleep quality in summer: a field study in Shanghai, China. Journal of Thermal Biology. 2021;99, 102977. http://doi.org/10.1016/j.jtherbio.2021.102977.

107. An R, Liu G, Khan N, Yan H, Wang Y. Dietary habits and cognitive impairment risk among oldest-old Chinese. Journals of Gerontology. 2017;74(3), 474-83. http://doi.org/10.1093/geronb/gbw170. 
108. Gehlich KH, Beller J, Lange-Asschenfeldt B, Köcher W, Meinke MC, Lademann J. Fruit and vegetable consumption is associated with improved mental and cognitive health in older adults from nonWestern developing countries. Public Health Nutrition. 2019;22(4), 689-96. http://doi.org/10.1017/S1368980018002525.

109. Gildner TE, Salinas-Rodríguez A, Manrique-Espinoza B, Moreno-Tamayo K, Kowal P. Does poor sleep impair cognition during aging? Longitudinal associations between changes in sleep duration and cognitive performance among older Mexican adults. Archives of Gerontology \& Geriatricg. 2019;83, 161-8. http://doi.org/10.1016/j.archger.2019.04.014.

110. An R, Xiang X, Liu J, Guan C. Diet and self-rated health among oldest-old Chinese. Archives of Gerontology \& Geriatrics. 2018;76, 125-32. http://doi.org/10.1016/j.archger.2018.02.011.

111. Patel SR, Ayas NT, Malhotra MR, White DP, Schernhammer ES, Speizer FE, Stampfer MJ, Hu F. A prospective study of sleep duration and mortality risk in women. Sleep. 2004;27(3), 440-4. http://doi.org/10.1093/sleep/27.3.440.

112. Yang L, Yang H, He M, Pan A, Li X, Min X, Zhang C, Xu C, Zhu X, Yuan J. Longer sleep duration and midday napping are associated with a higher risk of $\mathrm{CHD}$ incidence in middle-aged and older Chinese: The Dongfeng-Tongji cohort study. Sleep. 2016;39(3), 645-52. http://doi.org/10.5665/sleep.5544.

\section{Supplementary Files}

This is a list of supplementary files associated with this preprint. Click to download.

- AppendixR0Final.docx 